\title{
On the strength of the terrestrial magnetic field in buildings
}

\section{Aimé Witz}

To cite this article: M. Aimé Witz (1887) On the strength of the terrestrial magnetic field in buildings, Philosophical Magazine Series 5, 23:143, 381-384, DOI: 10.1080/14786448708628475

To link to this article: http://dx.doi.org/10.1080/14786448708628475

Published online: 29 Apr 2009.

Submit your article to this journal \lceil

Џll Article views: 2

Q View related articles $\square$ 
a process of his own is the same as one of mine, though it is not; he says that I sometimes suppose the free time to be constant, and sometimes to depend on the number of atoms, when I do not; and, lastly, that I have not stated what meaning I attach to $\tau$, when on page 238 , line 44 , I have defined it to be the free time multiplied by the number of atoms. I am, Gentlemen, Your obedient servant,

Trinity College, Cambridge, Feb. 14, 1887.

Ј. J. Thomson.

XLIV. Intelligence and Miscellaneous Articles.

ON CERTAIN MODIFICATIONS OF A FORM OF SPHERICAL INTEGRATOR,

To the Editors of the Philosophical Magazine and Journal.

GantLemen,

THAD occasion recently to read in the Philosophical Magazine 1 (August 1886) the very interesting description of a "Spherical Integrator," designed by Mr. Frederick John Smith, and which appears to be a modification of that of Prof. Hele Shaw. But the first conception of these apparatus, and it is to this that I wish to call your attention, belongs without doubt to me, as in No. 630 of "Nature (Nov. 24, 1881) I gave a description of an "Anemometer Integrator" founded on the same principle, and which was afterwards mentioned in the Quarterly Journal of the Royal Meteorological Society, No. 43(1882), by Mr Laughton ("Historical Sketch of Anemometry and Anemometers").

The modification designed by Mr. F. J. Smith tending to do away with or lessen, as much as possible, the moment of inertia of the sphere, appears to me excellent, especially if it is to transmit velocities of small magnitude. But when it is simply required to register that of the wind upon a moderate scale, I believe that the primitive form suffices; and after several trials which I have made, an ivory ball rolling on bronze cylinders is that which gives the best results.

I beg, Gentlemen, that you will allow this claim of priority to appear in your valuable Journal, and also that you will accept my most sincere thanks and the assurance of my marked regard.

Madrid Observatory, March 12, 1887.

V. VENTOSA.

\section{ON TEE STRENGTH OF THE TERRESTRIAL MAGNETIC FIELD \\ IN BUILUINGS. BY M. AIMÉ WITZ.}

In consequence of the removal of my laboratory to a new building in which the joists and framework are of iron, I have been led to determine exactly the values of the horizontal component in the various rooms used for Physics, with a view to certain researches which I have undertaken. I have observed 
astonishing discrepancies ; and I think it useful to draw the attention of physicists to this subject, which has been but little studied.

A simple method of measuring the horizontal intensity consists in passing a constant current through a circuit containing a weight voltameter, and a tangent-galvanometer. By determining the absolute strength of the current on the one hand by the results of electrolysis, and on the other by the deflection of a compassneedle, and equating these two values, we can get the value of $T$ at the spot where the galvanometer was placed. This method was of sufficient exactitude for the work of comparison in which $I$ was engaged.

A Poggendorff's battery may be used; this is a very constant source when the chromic liquid is strongly acid, and the external resistance is great. As an electrolyte I took a 10 per cent. solution of pure copper sulphate; the copper electrodes at a distance of about $30 \mathrm{~mm}$. had 12 square centimetres immersed; from this resulted a favourable density of current, and therefore a beautiful deposit of metal which was continuous and perfectly adherent. The loss of the soluble electrode was always equal to within $5 \mathrm{mgr}$. to the gain of the negative electrode. The intensity of the current, which was about $\frac{1}{3}$ of an ampere, was determined to within $\frac{1}{2000}$ of an ampere; it was assumed that $1190 \mathrm{mgr}$. was deposited per ampere-hour. Two good tangent-galvanometers were used simultaneously; their constants are as follows :-

\begin{tabular}{|c|c|c|c|c|c|}
\hline \multirow[b]{2}{*}{$\begin{array}{c}\text { Galva- } \\
\text { nometer. }\end{array}$} & \multicolumn{2}{|c|}{ Length } & \multirow{2}{*}{$\begin{array}{c}\text { Mean } \\
\text { radius. } \\
\text { R. } \\
\text { cm. }\end{array}$} & \multirow{2}{*}{$\begin{array}{c}\text { Number } \\
\text { of } \\
\text { windings. }\end{array}$} & \multirow[b]{2}{*}{$\frac{\mathrm{R} .}{2 \pi n}$} \\
\hline & $\begin{array}{l}\text { of needle } \\
\text { mm. }\end{array}$ & $\begin{array}{l}\text { of wire } \\
\text { mm. }\end{array}$ & & & \\
\hline & 15 & 1258 & $16 \cdot 68$ & 12 & 0.221 \\
\hline B & 20 & 1114 & $16 \cdot 12$ & 11 & 0.233 \\
\hline
\end{tabular}

The needles are suspended to a cocoon-thread; the long pointers of aluminum enable us to read $\frac{1}{10}$ of a degree. The relative dimensions of the needles and of the frames are in these two instruments in such a ratio, that we may dispense with the use of the term of correction, which I have considered proportional to the tangent of the deflection $\delta$.

The manipulation was very simple; the element having been shortcircuited for a few minutes, the current was passed for an hour through the roltameter and the galvanometer. Two double readings were made after five and twenty-five minutes; the current being reversed in the galvanometer after thirty-five and fifty-five minutes. The mean of these eight readings gives the value of the mean deflection of the needle in the course of the operation. It remained to weigh the electrodes, and to take the mean $p$ of the loss and gain of the plates in milligrammes. The formula

$$
\frac{1}{10} \frac{p}{1190}=\frac{R}{2 \pi n} \mathrm{~T}=\tan \delta
$$

leads to the value of $T$ in C.G.S. units; and the same operations repeated in various places enable us to discover considerable 
variations of the horizontal component in a building where much iron bas been used in the construction.

The following are the details of an experiment; they enable us to judge of the value of the method, and the agreement of the observations. This experiment was made on the 13th April 1886, at La Solitude in the suburbs of Lille, in the centre of an open space of several acres, and at a distance from any buildings and from water- or gas-pipes.

Deflections of the Galvanometer.

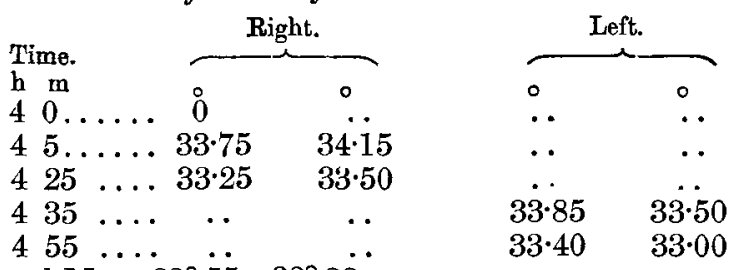

General Mean $33^{\circ} \cdot \dot{5} 5=33^{\circ} \cdot 33$.

$$
\begin{aligned}
& \text { Observations of the Voltameter. } \\
& \text { Loss of the Soluble Electrode } \ldots \ldots \ldots \ldots .360 \\
& \text { Gain of the Negative Electrode } \ldots \ldots \ldots .355 \\
& \text { Mean } \ldots \ldots \ldots \ldots \ldots \ldots \ldots \\
& \qquad \frac{1}{10} \frac{357 \cdot 5}{1190}=0.233 \mathrm{~T} \tan 33 \cdot 33 . \\
& \mathrm{T}=0.187 .
\end{aligned}
$$

This value of $T$ will serve as a point of comparison; it is less than the value observed at Paris on the 1st January 1886, as was to be expected from the position of Lille. We consider it exact to within 3 or 4 thousandths ; in fact an observation made after the first gave $0 \cdot 185$, and a great many experiments made in the laboratory showed that the result of an experiment never differs by more than $\frac{4}{1.000}$ from the mean of a month of investigations.

The table given below gives the value of $\mathrm{T}$ obtained in various parts of our establishment.

$$
\text { Place. Date. T. }
$$

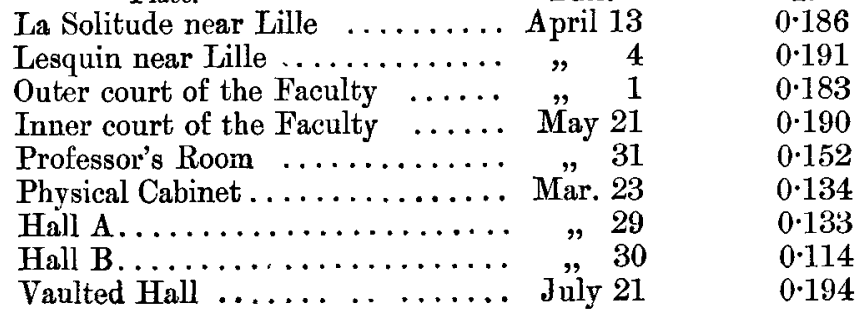

It follows from these researches that $T$ may be reduced by 40 or 50 per cent. in a building made of iron; hence the same current will give in the same galvanometer a deflection of $33^{\circ}$ to $45^{\circ}$ 
according to its position. It will thus be seen that the calibration of instruments of this kind must not be forgotten when they are moved from one place to another.-Journal de Physique, Jan. 1887.

\section{ON METALLIC LAYERS WHICH RESULT FROM THE VOLATILIZA-} TION OF A KATHODE. BY BERNHARD DESSAU.

The results of the present investigation may be summed up as follows :-

By appropriate electrical discharge in highly rarefied spaces, the metal which acts as kathode is volatilized and settles on a glass plate as a reflecting layer or mirror. If the oxygen has not been most carefully removed, all metals seem to undergo oxidation under these circumstances. There is perhaps in all cases a combination with the traces of residual gas (hydrogen or nitrogen), yet the mirrors obtained in hydrogen are not materially different from those of pure metals. With suitable arrangement of the electrodes the layer of metal is obtained as a flat cone; and when viewed in reflected light, under as acute an angle as possible, coloured interference-rings are obtained, which prove the presence of a dispersion in the metals. It may be concluded with some certainty that this dispersion is normal in platinum, iron, nickel, and silver, and abnormal with gold and copper. The layer directly produced by the discharge, whether it be metal or oxide, is always double refracting, probably in consequence of an electrical repulsion between the particles expelled, and the regular stratification thereby produced; in the metals the ray which vibrates tangentially is accelerated in respect of the others. In the metals the cross of double refraction was also observed in reflected light, and in reflection from the metal side the action was the reverse, and from the glass side the same as in transmitted light. Double refraction disappears on oxidation of the doublerefracting metals, as well as by reduction of the layers of oxirle, while heating without any chemical change has no effect.-Wiedemann's Annalen, No. 11, 1886.

\section{ON THE PASSAGE OF THE ELECTRIC CURRENT THROUGH AIR}

UNDER ORDINARY CIRCUMS'IANCES. BY J. BORGMANN.

One end of the coil of a Wiedemann's galvanometer is connected with the earth, and the other with a platinum wire, which is placed in the flame of $2 n$ insulated spirit-lamp. At a distance of $1 \frac{1}{2}$ metre from this lamp is an ordinary Bunsen burner, which is connected with a conductor of the Holtz machine; the other conductor is put to earth.

When the lamp is lighted the galvanometer indicates no current; but when the disk is rotated a distinct current at once appears in the galvanometer, and the defiection of the needle does not alter so long as the machine works at a uniform rate. If the Bunsen burner is connected with the other conductor of the machine, a current in the opposite direction is at once set up.-Beiblätter der Physik, January 1887. 